\title{
CONSTANTINO E A LEGITIMAÇÃO DO PODER IMPERIAL NO SÉCULO IV D.C.: UM ESTUDO DO PANEGÍRICO LATINO DE 310.
}

Ana Paula Franchi

A delimitação temática deste trabalho remete-se a ascensão de Constantino ao poder imperial no século IV d.C $\mathrm{C}^{1}$. Ao estudar este período, deparamos-nos com uma ampla discussão em torno das permanências e rupturas do mesmo em relação à Antiguidade Clássica. Entendemos, entretanto, este momento como uma transição, onde as estruturas que até então haviam fundamentado o Império Romano paulatinamente se transformam em direção a uma monarquia de caráter sagrado, que se concretizará com o governo de Constantino e seus sucessores.

Porém, para uma melhor compreensão deste processo, é necessário retroceder até o século III, momento em que constatamos um processo de deslocamento do eixo do poder imperial. Cabe ressaltar que a crescente dominação política do Império Romano só havia se tornado realidade a partir de alianças ocorridas entre a aristocracia senatorial romana e as elites locais e regionais, e que estas alianças, fundamentadas pela ciuitas, sinalizavam a participação destas elites locais no universo romano de fato.

Contudo, Frighetto ${ }^{2}$ enfatiza que a partir do século II, devido a tensões tanto de caráter interno como externo, a ciuitas começou a reduzir paulatinamente sua importância em termos políticos e institucionais. Este fato acabou enfraquecendo as instituições municipais, que deixaram de impulsionar as carreiras públicas, e

\footnotetext{
${ }^{1}$ Todas as datas deste trabalho se remetem ao período posterior ao nascimento de Cristo, salvo quando destacado o contrário.

2 FRIGHETTO, R. Estruturas sociais na Antiguidade Tardia Ocidental (séculos IV/VIII). In: SILVA, G. V. da; MENDES, N. M. Repensando o Império Romano: perspectivas socioeconômicas, política e cultural. Rio de Janeiro e Vitória: Maud Editora e EDUFES, 2006, p. 226.
} 
tornaram-se pouco interessantes aos membros das aristocracias locais e regionais. Desta forma, os poderes regionais começaram a aparecer como concorrentes do poder imperial central, que não mais respondia as necessidades deste setor.

Outra forma de inserção destas elites provincianas locais e regionais no eixo do poder deu-se através dos exércitos. Este também vinha se transformando desde o século I a.C., com o crescente vínculo entre os legionários e seus generais. Os soldados buscavam em seus generais uma reabilitação econômica (uma vez que, segundo Anderson, "os generais vitoriosos, que podiam garantir as pilhagens de seus soldados ou os donativos por seu poder pessoal" "), e os generais, em contrapartida, apoiavam-se em seus soldados para algum avanço político.

Ao mesmo tempo, a própria composição do exército havia mudado. Como este meio estava destacando-se como uma das formas de progressão social, o número de provincianos (e até mesmo bárbaros aliados) aumentou dentro das legiões. Logo, o advento do poder imperial passou com regularidade aos generais proveniente de regiões fora da península Itálica.

A partir destes fatos, constatou-se uma série de usurpações deste poder por parte dos generais das tropas. Todavia, estas usurpações só tinham êxito devido à fragilidade do Império neste momento, que além de sofrer com uma crise econômica e política, sofria fortes pressões nas suas fronteiras.

Inúmeros imperadores oriundos do exército ascenderam ao poder neste período que engloba os anos de 235 e 284 (ano do advento de Diocleciano à púrpura imperial), o que possibilitou a caracterização do mesmo sob a nomenclatura "Anarquia Militar". Um dos principais obstáculos para o fim desta instabilidade política e das usurpações, fora a impossibilidade de se organizar novas dinastias no poder, devido a grande dificuldade de se implantar uma política sucessória coerente.

3 ANDERSON, P. Passagens da Antiguidade ao Feudalismo. São Paulo: Brasiliense, 2007, p. 65. 
Neste sentido, a reestruturação do sistema imperial proposta por Diocleciano traria grandes frutos. Esta reorganização primava por mudanças político-administrativas e sociais, acarretando em uma maior possibilidade de controle do Estado sobre a vida pública. Dentre as inovações realizadas por Diocleciano, destacou-se a criação da Tetrarquia, que dividiu a administração do Império entre dois ou mais titulares, buscando a manutenção do Império e a defesa do amplo território controlado pelos romanos.

Logo nos primeiros anos do governo de Diocleciano, a organização do Império se fundamentou na divisão do poder entre dois augustos e dois césares, cada qual responsável pela administração e defesa de uma parcela do território imperial, com capital própria. Embora dividida, esta organização imperial seguia uma hierarquia.

No ápice, se encontrava Diocleciano, dito Iovius, i.e, descendente de Júpiter, que comandava o Império na qualidade de Augustus sênior. Em seguida, temos seu auxiliar direto, Maximiano, dito Herculius. Abaixo vinham os césares Galério e Constâncio Cloro. ${ }^{4}$

Pretendia-se neste sentido, consolidar o fim das usurpações do poder imperial, pois em caso de morte ou decorridos vinte anos de governo, os césares assumiriam o encargo de augustos, nomeando novos césares como seus sucessores. Porém, a renúncia de Diocleciano em 305 d.C., seguida a contragosto por Maximiano, desmascarou uma fragilidade deste sistema sucessório, que se apoiava sob o principio de adoção política ${ }^{5}$ e casamento, deixando a hereditariedade em segundo plano.

\footnotetext{
${ }^{4}$ SILVA, G. V. da; MENDES, N. M. Diocleciano e Constantino: a construção do DOMINATO. In: SILVA, G. V. da; MENDES, N. M. Repensando o Império Romano: perspectivas socioeconômicas, politica e cultural. Rio de Janeiro e Vitória: Maud Editora e EDUFES, 2006, p. 199.

5 HIDALGO DE LA VEGA destaca em El intelectual, la realeza y el poder político en el Império Romano. Salamanca: Universidad de Salamanca, 1995, que a adoptio se fazia em funções das qualidades morais do adotado, e não por sucessão dinástica.
} 
Elevaram-se ao posto de augusto, Galério e Constâncio Cloro, e a divergência surge com a nomeação dos novos césares (Maximino Daia e Severo), pois Maxêncio e Constantino (filhos de Maximiano e Constâncio Cloro respectivamente) reclamam seus direitos baseados no princípio da hereditariedade.

Com a morte de seu pai em 306 d.C., Constantino evoca para si o poder imperial, sendo aclamado augusto por suas tropas na Gália, resgatando, portanto, a influência do poderio militar como um eficaz instrumento de ascensão ao poder. Porém, a aclamação de Constantino daria abertura ao reaparecimento das disputas e usurpações em torno do poder imperial, atitude que foi seguida de imediato por Maxêncio.

Após o curto período de estabilidade política proporcionado pela Tetrarquia, e o reaparecimento das disputas em torno do poder, os aspirantes ao poder imperial perceberam que somente a aclamação militar não seria garantia de estabilidade e permanência, e passaram a se apoiar em diversos outros artifícios para garantir sua legitimação perante o Império.

Percebemos também durante o século III e IV, em decorrência de todo este contexto de transformações, uma mudança teórica no que diz respeito ao poder do governante. Até o Principado, este poder era configurado por uma estreita relação entre o imperador e a aristocracia senatorial principalmente. A associação entre o poder imperial e símbolos do âmbito sagrado era uma realidade, principalmente pela influência helênica, todavia esta prática foi potencializada no século IV através de construções teóricas que buscavam consolidar um poder monárquico centralizado. Desta forma, o imperador passa a surgir como "dominus e quase diuus, colocando-se numa posição mais forte em comparação com as demais instituições e grupos sociais que o amparavam"6.

${ }^{6}$ FRIGHETTO, R. Estruturas sociais na Antiguidade Tardia Ocidental (séculos IV/VIII). In: SILVA, G. V. da; MENDES, N. M. Repensando o Império Romano: perspectivas socioeconômicas, política e cultural. Rio de Janeiro e Vitória: Maud Editora e EDUFES, 2006, p. 226. 
Neste contexto, obras como os panegíricos apareceram como instrumentos importantes. A produção panegirista teve um aumento considerável, principalmente as que louvam a imagem de diferentes imperadores. Constantino foi homenageado em um número considerável de panegíricos, e, utilizou-se desta produção para consolidar as bases do Dominato e se legitimar como único imperador.

O discurso panegirístico é extremamente recorrente dentre as variadas produções escritas no Império Romano. É considerado por diversos autores como um discurso que atravessa os limites da literatura tal qual a compreendemos atualmente. Carvalho ${ }^{7}$ destaca que independente do tipo de discurso e da época de sua elaboração, eles podem mascarar interesses políticos e culturais.

Pode-se considerar, neste sentido, a linguagem como um instrumento ativo de poder, em vez de simplesmente refletir uma dada realidade política e social. Constatamos, portanto, a ampla utilização dos panegíricos como instrumentos de construção ideológica e propaganda política, tanto de personagens, quanto de localidades que se destacaram pela importância administrativa e econômica durante o Império Romano.

Este tipo de discurso era comum na Antigüidade. Utilizado originalmente na Grécia Antiga, era pronunciado em determinadas assembléias solenes, e sua construção tinha como base a oratória e a retórica. Entretanto, somente a partir de 380 a.C., é que os panegíricos se converteram em orações laudatórias destinadas a celebrar a glória das cidades ou de indivíduos em particular ${ }^{8}$.

É com esta caracterização que este gênero discursivo aparece no século IV, tendo como centro a exaltação das virtudes e feitos

${ }^{7}$ CARVAlho, M. M. de. Paidéia e retórica no séc. IV $d$. C.: a construção da imagem do imperador Juliano segundo Gregório de Nazianzeno, Tese de Doutorado, São Paulo: Universidade de São Paulo, 2002, p. 09.

${ }^{8}$ OLIVEIRA, M. A. M. O Império Romano e o Reino dos Céus: a construção da imagem sagrada do imperador em De Laudibus Constantini, de Eusébio de Cesaréia. Dissertação de Mestrado. Vitória: Universidade Federal do Espírito Santo, 2005, p. 20-21. 
relevantes de um personagem, um lugar ou um acontecimento. Desta forma, ao propor o estudo dos panegíricos como uma das bases utilizadas por Constantino em sua legitimação no poder, pressupõese que a linguagem não seja desvinculada da vida social e política no Império Romano, e que seria utilizada muitas vezes com o objetivo de adequar uma forma de poder político à nova realidade histórica que se desenvolvia nesta época.

Dentro deste contexto, os panegíricos eram encomendados aos oradores mais respeitados de cada município, e adquiriam assim o status de documento de circulação oficial no Império Romano.

Atuando decisivamente na adaptação da retórica à comunicação política no Império Romano, os panegíricos pronunciados em presença do imperador adquirem status de documentos oficiais de primeira ordem, por conterem declarações políticas orientadas, e eventualmente, ditadas pelo imperador. ${ }^{9}$

Com o status de documentação oficial, o orador organizava sua estratégia discursiva em função de acontecimentos recorrentes do momento que participava, resgatando fatos e personagens "gloriosos", buscando relacioná-los com o homenageado em questão, uma vez que a produção panegirista passa a ser considerada praticamente obrigatória após algum feito glorioso do Imperador:

En líneas generales los panegíricos se pronuncian por las fiestas de un nuevo año, la ascención ao poder de un aspirante al imperio o por una campaña victoriosa contra los enemigos del Estado: usurpadores o bárbaros; siendo el objetivo final la adaptación de la retórica a la comunicación política. Los panegiristas con tal fin difunden e amplían la propaganda imperial, formulando, en definitiva, las bases teóricas de la política oficial. $^{10}$

\footnotetext{
${ }^{9}$ OLIVEIRA, M. A. M. O Império Romano e o Reino dos Céus: a construção da imagem sagrada do imperador em De Laudibus Constantini, de Eusébio de Cesaréia. Dissertação de Mestrado. Vitória: Universidade Federal do Espírito Santo, 2005, p. 117.

${ }^{10}$ GERVÁS, Manuel J. Rodrigues. Propaganda Politica y Opinión Pública en los panegíricos latinos Del bajo império. Univearsidade de Salamanca: Salamanca, 1991, p. 27.
} 
Em relação à produção panegirista do final do século III e início do IV, se considerarmos principalmente a freqüência com que estes discursos foram produzidos e pronunciados, perceberemos a ênfase em seu caráter propagandístico e ideológico. A própria utilização da retórica e oratória na elaboração dos mesmos dá sinais sobre a intenção dos autores, que buscam conduzir o ouvinte a crer no que está sendo exposto. Estes fatos destacam a importância que estas obras teriam na construção e consolidação do novo quadro político-ideológico do Dominato, que iniciou com a ascensão de Diocleciano ao poder imperial.

Dentre a extensa produção panegirista em homenagem ao imperador Constantino foi selecionado o discurso pronunciado no ano de 310, "Panegírico de Constantino", pois esta obra nos possibilita uma análise mais detalhada de como os panegíricos eram utilizados como instrumentos de promoção ideológica, uma vez que foi produzido após o rompimento da aliança entre Constantino e Maximiano.

Contudo, os demais discursos em honra a este imperador, datados dos anos de 307, 312, 313, 321, não puderam ser desconsiderados. Seus autores seguem uma mesma estrutura de discurso, iniciando com uma ordem cronológica dos acontecimentos, e resgatando, logo nos primeiros parágrafos, a importância do personagem a quem o discurso é dedicado, para depois prosseguir com os argumentos em prol de sua legitimação. Podemos perceber também, que alguns destes autores acabam recorrendo com freqüência a outros discursos pronunciados anteriormente.

Após a aclamação como augusto pelo seu exército em 306, Constantino buscou alianças políticas, sendo a primeira com Maximiano, visando um reconhecimento institucional do título obtido, pois desta forma, ele estaria sendo aclamado augusto por um outro augusto legítimo, embora o último tenha renunciado junto com Diocleciano em 305, devido aos laços de fidelidade, havia retornado ao cenário político imperial em 306 , retomando sua posição enquanto augusto. O discurso de 307, "Panegírico em honor de Maximiano y 
Constantino", pronunciado em circunstância do casamento de Constantino e Fausta vêm para exaltar esta união.

Entonces Maximiano [...], huyó a la Gália en busca de la alianza de Constantino: se hizo reconocer Augusto por él y le dio a su vez este mismo título y la mano de su hija Fausta.

O orador do panegírico de 307 ao abordar no decorrer de seu discurso a união de Constantino com Maximiano construiu a legitimação de ambos com base na linhagem familiar (pela adoptio, Constâncio Cloro era herdeiro de Maximiano), possibilitando a construção de uma política sucessória com princípios dinásticos e sagrados, principalmente ao afirmar a ligação com Hércules:

Vosotros, en efecto, perpetuais la república no con una descendencia plebeya, sino con una descendencia doblemente imperial [...] se prolongue en los tiempos futuros bajo emperadores que seam siempre descendientes de Hércules. ${ }^{12}$

Com o fim desta aliança, o orador de 310 necessitou encontrar novos elementos para exaltar o então vitorioso Constantino, porém, sua argumentação em prol da legitimidade continuou baseada em uma linhagem familiar, mas neste momento a ligação com Maximiano foi silenciada, sendo ressaltada seu parentesco com Cláudio o Gótico (que teve grande repercussão ao derrotar os alamanos e os godos durante o período da Anarquia Militar). O orador também não abandonou a ligação com o sagrado como princípio para a legitimidade (forte característica do Dominato), mas para que não se existisse mais nenhuma associação entre Maximiano e Constantino, a devoção deste último transferiu-se para o culto a Apolo:

[...] el panegirista de 310 es testigo de este giro en las creencias oficiales del principe y del favor especial que adquiere el diós Apolo para él. De

\footnotetext{
${ }^{11}$ LLORENTE, Victor-José H. (trad.) Biografos y panegiristas latinos. Tollf, Lege. Aguilar. p. 1197.

12 An., Paneg. 307 (II, 5) In: LLORENTE, Victor-José H. (trad.) Biografos y panegiristas latinos. Madri. Tollf, Lege. Aguilar, 1969, p. 1205.
} 
hecho, esto era una vuelta a la religión querida de los antepasados, ya que Cláudio II hacia representar el sol en el reverso de sus monedas y supuesto que Constantino se inclinaba hacia una especie de monoteísmo solar. ${ }^{13}$

Esta preocupação de Constantino em estabelecer uma linhagem divina como instrumento de legitimação está presente em todos os panegíricos selecionados. Embora o orador do discurso de 321, "Panegírico de Constantino Augusto" não nomeie este divino, como no caso de Hércules ou Apolo, buscou em sua fala deixar claro que "desde su subida al poder, Constantino había sido objeto de una especial elección divina"14.

Um aspecto que merece destaque no discurso de 310 é o relato feito pelo orador a respeito da morte de Maximiano, justificando-a a partir de suas pretensões dinásticas contra Constantino, seguido dos novos rumos traçados em relação às crenças religiosas. Este acontecimento gerou muita repercussão, uma vez que Maximiano foi condenado por Constantino a cometer suicídio voluntário, sob a alegação de traição ${ }^{15}$.

En cuanto a él, creo que en el momento en que había de ser dado aluz y en que tênia que elegir la existencia que habia de ser la suya, fue a caer en una suerte que no podia eludir una suerte que habia de provocar injustamente numerosas muertes y había de conducir-le a él mismo al fin de una muerte voluntária. ${ }^{16}$

É interessante observar, que, na busca pela dissociação da imagem de Constantino em relação à Maximiano, o autor do panegírico de 310 omitiu qualquer referência nominal ao mesmo, e

${ }^{13}$ LLORENTE, Victor-José H. (trad.) Biografos y panegiristas latinos. Madri. Tollf, Lege. Aguilar, 1969, p. 1216.

${ }^{14}$ Ibidem, p. 1272.

15 ALENCAR, R. D. de. Memória e poder nos panegíricos de Constantino. Disponível em: http://www.assis.unesp.br/neam/anais2006/texto14.pdf. Acesso em 08/08/2007, p. 5.

${ }^{16}$ An., Paneg. 310 (XIV, 5) In: LLORENTE, Victor-José H. (trad.) Biografos y panegiristas latinos. Madri. Tollf, Lege. Aguilar, 1969, p. 1224. 
quando esta abordagem tornou-se inevitável, a referência à Maximiano é verificada como "aquel hombre".

Entretanto, a literatura panegirista também preocupou-se em afastar a imagem de Constantino da associação com os demais usurpadores. Neste sentido, percebemos durante o período da história do Império Romano, grandes preocupações dos intelectuais em fundamentar a legitimidade de seus soberanos teorizando sobre o que seria o bom príncipe, utilizando as virtudes imperiais como principal argumentação, em oposição aos tiranos ou usurpadores.

As virtudes imperiais buscavam elaborar, formalizar e intensificar a imagem imperial na perspectiva de participar como um fator a mais na construção de uma teoria política em torno da realeza ${ }^{17}$. Em boa parte das produções do século IV, percebemos esta tentativa em se aperfeiçoar a imagem do imperador celebrado em contraste com a do seu opositor.

$\mathrm{O}$ inimigo que aspirava ao poder arbitrariamente era considerado um usurpador, ilegítimo, que havia tentado tirar o poder do príncipe legítimo. Neste sentido, os usurpadores, desprovidos das virtudes relativas ao princeps, foram utilizados, através da literatura oficial, como justificativa para a realização de determinadas ações por parte do poder legitimamente instituído.

[...] la literatura laudatória bajo la forma de panegírico conservada, dentro de la qual el usurpador cumple la función de antagonista respcto del legítimo emperador, mientras su denegricion permite la optimización del princeps. ${ }^{18}$

Porém, o conceito usurpare (apoderar-se de algo sem direito) sofreu uma reestruturação consolidada pela produção panegirista no século IV, principalmente no período constantiniano. Com a política

\footnotetext{
${ }^{17}$ HIDALGO DE LA VEGA, M. J. El intelectual, la realeza y el poder politico en el Império Romano. Salamanca: Universidad de Salamanca, 1995, p. 110.

${ }^{18}$ ESCRIBANO, M. V. Usurpación y religión en el s.IV D. de C. - paganismo, cristianismo y legitimactión política. IN: BLANCO, A. G. Antigüedad y cristianismo - monografías históricas sobre la antigüedad tardía. Universidade de Murcia, 1990, p. 248.
} 
de legitimação do poder, observou-se nas obras laudatórias, a justaposição dos conceitos de usurpação e tirania.

Tirano, antes utilizado somente para caracterizar o imperador que exerceu o poder de forma arbitrária, normalmente após o fim de seu governo, em associação com usurpador, tornou-se sinônimo de alteridade política negativa para com o atual imperador, servindo de contraponto para louvar e legitimar a imagem do "Bom Príncipe".

Igualar en el âmbito nominal al usurpador con el tirano comportaba concentrar en él toda la semántica adquirida por su figura como símbolo de la alteridad política negativa respecto del poder instituído, desde su gestación $[\ldots]^{19}$.

Ficava então ao encargo dos panegiristas do século IV, distanciar a imagem do Imperador (encarnação de todas as virtudes) do tyrannus-usurpator, principalmente com o auxilio da retórica e da utilização das virtudes imperiais em seus discursos.

Ao fim e ao cabo, esta associação de conceitos surge como mais um apoio à teoria desenvolvida para a legitimação política de Constantino, tendo em vista justificar o modo como este imperador ascendeu ao poder, procurando afasta-lo da imagem de usurpador ${ }^{20}$. É em decorrência deste fato que os oradores dos panegíricos em seu louvor procuram ressaltar a legitimidade de Constantino através de sua linhagem familiar e direito hereditário.

[...] tu, Constantino, tiene el privilegio de haber nacido emperador, y es tal la nobleza de tu origen, que tu promoción al imperio no ha venido a añadir nada a tu dignidad y la fortuna no puede prevalerse ante ti de lo que te pertenece en propiedad, sin intrigas y sin recomendaciones. No ha sido el

${ }^{19}$ ESCRIBANO, M. V. Usurpación y religión en el s.IV D. de C. - paganismo, cristianismo y legitimactión política. IN: BLANCO, A. G. Antigüedad y cristianismo - monografías históricas sobre la antigüedad tardía. Universidade de Murcia, 1990, p. 250.

20 Uma vez fora da sucessão tetrárquica, ao ser aclamado por suas tropas, Constantino pode ser considerado um usurpador do poder imperial. 
acuerdo accidental de los hombres ni un soplo súbito del favor lo que ha hecho de ti un príncipe: mereciste el imperio en virtud de tu nacimiento. ${ }^{21}$

Em decorrência destas questões, podemos perceber que o governo do imperador Constantino é uma clara continuidade das mudanças que o Império Romano sofreu desde aproximadamente o século III. Neste momento, embora constatemos uma grande instabilidade política, foram os generais que tomaram a púrpura que abriram caminho para a reorganização de toda a estrutura do Estado Romano iniciada por Diocleciano.

A ascensão de Constantino ao poder está, portanto, diretamente ligada a este crescimento da influência militar na nomeação dos soberanos, e consequentemente, do aumento da importância das regiões provincianas no Império, uma vez que ele tinha grande prestígio entre as tropas estabelecidas na Gália. A influência destes novos setores na política imperial possibilitou uma incorporação de práticas culturais que fundamentaram o Dominato, como por exemplo, a divinização dos monarcas, ideologia geral do mundo helênico, que respondia as necessidades desta nova realidade.

Neste sentido, a produção panegirista do século IV, que teria aparentemente o objetivo de louvar a imagem do soberano perante a população do Império (uma vez que eram pronunciados em ocasiões solenes e comemorações oficiais) foi utilizada como um importante instrumento propagandístico e ideológico neste contexto de instabilidade e transformações do modelo político imperial romano. Primeiro por ressaltar as campanhas realizadas durante o governo de Constantino, e principalmente por fundamentar sua legitimidade nos princípios dinásticos e sagrados que vieram a caracterizar o Dominato.

${ }^{21}$ An., Paneg. 310 (XIV, 5) In: LLORENTE, Victor-José H. (trad.) Biografos y panegiristas latinos. Madri. Tollf, Lege. Aguilar, 1969,. p. 1218. 


\section{BIBLIOGRAFIA}

ALENCAR, R. D. de. Memória e poder nos panegíricos de Constantino. Disponível http://www.assis.unesp.br/neam/anais2006/texto14.pdf. Acesso em: 08/08/2007.

ANDERSON, P. Passagens da Antiguidade ao Feudalismo. São Paulo: Brasiliense, 2007.

CARVAlho, M. M. de. Paidéia e retórica no séc. IV d. C.: a construção da imagem do imperador Juliano segundo Gregório de Nazianzeno. Tese de Doutorado. São Paulo: Universidade de São Paulo, 2002

ESCRIBANO, M. V. Usurpación y religión en el s.IV D. de C. paganismo, cristianismo y legitimactión política. IN: BLANCO, A. G. Antigüedad y cristianismo - monografías históricas sobre la antigüedad tardía. Universidade de Murcia, 1990.

. Constantino y la rescissio actorum del tirano-usurpator. Gerión, $\mathrm{n}^{\mathrm{o}}$ 16. Departamento de História Antiga - Facultad de Geografia y Historia. Servicio de publicaciones Universidad Complutense, 1998. P. 307-338.

GERVÁS, Manuel J. Rodrigues. Propaganda Politica y Opinión Pública em los panegíricos latinos Del bajo império. Univearsidade de Salamanca: Salamanca,1991

FRIGHETTO, R. Cultura e poder na Antiguidade Tardia ocidental. Curitiba: Juruá, 2003.

HIDALGO DE LA VEGA, M. J. El intelectual, la realeza y el poder político en el Império Romano. Salamanca: Universidad de Salamanca, 1995.

LLORENTE, Victor-José H. (trad.) Biografos y panegiristas latinos. Madri. Tollf, Lege. Aguilar, 1969.

OLIVEIRA, M. A. M. O Império Romano e o Reino dos Céus: a construção da imagem sagrada do imperador em De Laudibus Constantini, de Eusébio de Cesaréia. Dissertação de Mestrado. Vitória: Universidade Federal do Espírito Santo, 2005. 
Revista Vernáculo, n. 21 e 22, 2008

SILVA, G. V. da; MENDES, N. M. Repensando o Império Romano: perspectivas socioeconômicas, política e cultural. Rio de Janeiro e Vitória: Maud Editora e EDUFES, 2006. 